\title{
PROFILE OF PATIENTS IN H1N1 OUTBREAK IN 2015 IN A TERTIARY CARE HOSPITAL IN INDIA
}

\author{
Poornima Rangappaㄹ, Asima Banu², Gopalkrishna B. Huilgol³, Janani Rajkumar4
}

${ }^{1}$ Assistant Professor, Department of Surgery, Bangalore Medical College and Research Institute.

2 Professor, Department of Microbiology, Bangalore Medical College and Research Institute.

3 Professor, Department of Obstetrics and Gynaecology, Bangalore Medical College and Research Institute.

${ }^{4}$ Intern, Bangalore Medical College and Research Institute.

\section{ABSTRACT}

\section{BACKGROUND}

Influenza viruses circulate in human populations causing epidemics on an annual basis. Pandemics may occur with the formation of new strains. This study describes the profile of patients suffering from H1N1 influenza presenting to a tertiary care hospital, during the 2015 epidemic. Information regarding the sex distribution, age distribution, common clinical features (along with their duration), comorbid conditions and outcome has been analysed. Data regarding the distribution, associated factors and variations observed in relation to the 2009 pandemic would help in easier identification and supervision of cases in the future.

\section{MATERIALS AND METHODS}

The study was conducted in a tertiary care government hospital in Bangalore, attached to a medical college. Data regarding the common clinical features, the underlying medical condition and the treatment outcome of the patients who presented to the outpatient department, was analysed. A total of 105 suspects were screened from January 2015 to April 2015 and confirmation done by the Polymerase Chain Reaction.

\section{RESULTS}

During the study period, a total of 105 patients were tested for H1N1 of which 37 (35.24\%) were positive and most of them were from urban areas in Bangalore. The main presenting features were fever and diarrhoea. All patients were admitted to the ICU, given ventilator support, and treated with Oseltamivir and broad spectrum antibiotics. Average number of days of stay in ICU was 3.73 days per patient. $19(51.36 \%)$ of the patients died.

\section{CONCLUSION}

Unexpected outbreak of such a severity was successfully managed in a tertiary care, public sector hospital due to effective infection control policies and lessons learnt from the 2009 pandemic.

\section{KEYWORDS}

H1NI, Complications

HOW TO CITE THIS ARTICLE: Rangappa P, Banu A, Huilgol GB, et al. Profile of patients in H1N1 outbreak in 2015 in a tertiary care hospital in India. J. Evolution Med. Dent. Sci. 2016;5(78):5856-5859, DOI: 10.14260/jemds/2016/1320

\section{BACKGROUND}

H1N1 influenza, popularly known as "Swine Flu" is caused by a subtype of Influenza A viruses. Influenza viruses circulate in human populations causing epidemics on an annual basis. Occasionally, an antigenically new strain may arise, which could cause a pandemic. ${ }^{1}$ H1N1 was one such new strain, resulting from a reassortment between 4 viruses- 2 genes were from influenza viruses in pigs, and the last 2 were from bird and human influenza viruses. ${ }^{2}$ The first case H1N1 influenza was reported in Mexico in March 2009. It spread to over 214 countries worldwide. ${ }^{3}$ with the WHO raising the pandemic alert to phase 6 by June 2009.4 As of December 2009, the pandemic strain caused 967 deaths in 26,039 people who were diagnosed with the disease. A notable feature of this outbreak was the high morbidity and mortality observed in the younger age groups. ${ }^{5}$

Financial or Other, Competing Interest: None.

Submission 20-08-2016, Peer Review 16-09-2016,

Acceptance 23-09-2016, Published 29-09-2016.

Corresponding Author:

Dr. Asima Banu,

\# 34/1, Sree Ram Mandir Road, Basavanagudi,

Bangalore-560004.

E-mail: asima.banu@gmail.com

DOI: $10.14260 /$ jemds $/ 2016 / 1320$

\section{(c) $(1) \risingdotseq$}

Early in the year 2012, a re-emergence was noted. (6) As of March 2015, nearly 2035 people in India have died due to H1N1 influenza while the total number diagnosed stands at 33,761 . In the State of Karnataka, nearly 2733 cases have been diagnosed with 82 people dying as a result of the flu. ${ }^{7}$

Fever and cough are considered to be two of the hallmark symptoms of the disease along with breathlessness, fatigue, chills and myalgia. The symptoms are comparable to that of seasonal flu, with the exception of gastroenterological symptoms, such as vomiting and diarrhoea, which are more commonly associated with H1N1. ${ }^{8}$ It most usually presents as mild or subclinical pneumonia, but some cases present as severe community acquired pneumonia. It can further progress to acute lung injury/acute respiratory distress syndrome. In some situations, primary viral pneumonia with secondary bacterial infections may occur $(20-30 \%) .{ }^{9}$ The existence of underlying medical conditions (Pregnancy, chronic lung conditions) imposes a greater risk of complications and death associated with H1N1. ${ }^{9}$ Healthcare personnel are at increased risk of occupational exposure to the 2009 H1N1 virus, based on their likelihood of encountering patients with this illness. ${ }^{10}$

This study aims at analysing the profile of patients suffering from H1N1 influenza by accumulating information regarding the sex distribution, age distribution, common 
clinical features (along with their duration), comorbid conditions and outcome. Information regarding the distribution, associated factors and variations observed in relation to the 2009 pandemic would help in easier identification and supervision of cases in the future.

\section{MATERIALS AND METHODS}

The study was conducted in a tertiary care government hospital in Bangalore attached to a medical college. After obtaining permission from the superintendent of the institution, the information regarding the common clinical features, the underlying medical condition and the treatment outcome of the patients who presented to the outpatient department, was analysed. A total of 105 suspects were screened from January 2015 to April 2015. The throat and nasal swabs were collected in viral transport media and were sent to a government designated referral laboratory for testing and confirmation by the Polymerase Chain Reaction.

The patients who presented with flu-like symptoms were categorised into category A (patients with mild fever plus cough/sore throat with or without body ache, headache, diarrhoea and vomiting), category B (in addition to the signs and symptoms of category A), if the patient had high grade fever and severe sore throat or if the patient had one or more of the following high-risk conditions, like children who were less than 5 years old, pregnant women, persons who were aged 65 years or older, patients with lung diseases, heart disease, liver disease, kidney disease, blood disorders, diabetes, neurological disorders, cancer and HIV/AIDS and patients on long-term cortisone therapy and category $\mathrm{C}$ (in addition to the above signs and symptoms of categories $A$ and $\mathrm{B}$, if the patient had breathlessness, chest pain, drowsiness, fall in blood pressure, worsening of the underlying chronic conditions and among the small children, irritability, refusal to accept feeds). ${ }^{11}$

\section{RESULTS}

During the study period, a total of 105 patients were tested for H1N1 of which 37 (35.24\%) were positive, 16 male and 21 females. The age distribution of the patients is represented in Figure 1. Maximum numbers of cases were in the age groups of 30-39 years (8) and 40-49 years. $(8)$

The main presenting features were fever seen in 25 $(67.6 \%)$ patients and diarrhoea seen in $24(64.87 \%)$ of the patients who tested positive for H1N1. The distribution of presenting features is given in Figure 2. Most of the patients presented to the hospital with complaints of duration greater than 6 days. The distribution of duration of complaints is given in Figure 3. All of the cases were from Bangalore city, with the exception of one case from a rural area.

All patients were admitted to the ICU, given ventilator support, and treated with Oseltamivir and Broad Spectrum antibiotics. Average number of days of stay in ICU was 3.73 days per patient. $19(51.36 \%)$ of the patients died, 11 of bronchopneumonia and 8 of ARDS. $10(27.03 \%)$ patients who tested positive for H1N1 had associated comorbid conditions (Pregnancy, diabetes mellitus and hypertension).

\section{DISCUSSION}

With the fall of the global pandemic in 2010, there have been multiple outbreaks of H1N1 influenza in India in the intervening years.
The present resurgence of pandemic virus cannot be attributed to any single factor at this stage. In our study, a greater number of females were diagnosed positive as compared to males. This was in contrast to a study in Delhi in which males were predominantly affected.(12)

However, despite variations in incidence and severity following infection in males and females, the outcome of infection with 2009 H1N1 was generally worse for females, with variations across different communities.(13-15)

\section{The Skewed Sex Distribution can be Related to Several Factors such as}

1. Occupational Risk: Healthcare personnel, are at a higher risk of exposure to influenza viruses than the general public. Women are a significant part of this group putting them at a greater risk for contact with influenza. (11)

2. Personal Hygiene: One of the primary modes of transmission of influenza is through droplet aerosols, via contact. As a results hand washing forms one of the mainstays of preventing transmission, and this practice is significantly better among females. ${ }^{(16)}$

3. Health Care: While some studies report that women are more likely to seek medical advice, the quality of care received by them is often inferior compared to that of men, in parts of the world.(17)

4. Comorbid Conditions: Chronic medical conditions predispose patients to increased influenza-related morbidity.(18) This refers to the dissimilarities in incidence of respiratory, hepatic, cardiovascular, metabolic and immunodeficiency diseases between males and females.

5. Hormones: Sex hormones vary in their action on the immune system. This may contribute to the variation in sex distribution and the effects of pregnancy in cases of H1N1.

6. Vaccination: Trials involving the influenza vaccines have shown sex based variations in the rates of vaccination, antibody responses to the vaccines and adverse reactions to the vaccines. ${ }^{(19)}$

In this study of the 37 patients with H1N1, only 5 (13.5\%) required ICU admission. This was similar to the findings of Ramakrishna et al in which $22.8 \%$ of the patients required ICU treatment.(20)

This is significantly more than a study from Mexico in which $5.6 \%$ were admitted to the ICU.(21) but comparatively less than the figures from Australia, in which $26.8 \%$ were admitted to the ICU.(22)

In our study, most of the patients were in the age group of 30-49 years. However, most studies indicate the greatest disease burden for the 2009 epidemic in younger individuals (less than 25 years). $(3,23-25)$

It is also in contrast to peak periods of seasonal influenza, which is more common among people older than 65 years and those under the age of 5 years. (26)

This may be due to the fact that older people have preexisting immunity to the H1N1 virus as determined by serological and epidemiological studies.(8) In our study, the primary complaints were found to be fever, breathlessness and cough and the other symptoms were sore throat, 
headache, myalgia, lethargy/drowsiness, rhinorrhoea and chest pain.

This is in concordance with several studies, which have stated fever and respiratory symptoms to be characteristic of this condition. $(6,27-30)$

All of the patients had complaints of gastrointestinal symptoms such as pain abdomen, vomiting or diarrhoea. This is in contrast to a study by Tambe et al in which patients reported such complaints in addition to the others listed.(24)

Our study revealed that most of the patients sought medical help after more than 6 days of symptom presentation. This was in concordance with the report by Barclay, which suggested a relatively long period of illness prior to presentation to the hospital.(28)

However, a study by Basha et al revealed that most of the patients presented after two days of symptoms.(29)

A review of literature by Anand et al concluded that the prognosis of the disease was best when treatment started as early as 48 hours after appearance of symptoms. ${ }^{30)}$

\section{CONCLUSION}

Compared to the 2009 pandemic, 2015 outbreak was more severe and had more morbidity. The healthcare personnel were more aware and better equipped to handle a sudden resurgence. This influenza outbreak affected young people without comorbid conditions, which indicate no prior immunity in the affected population.

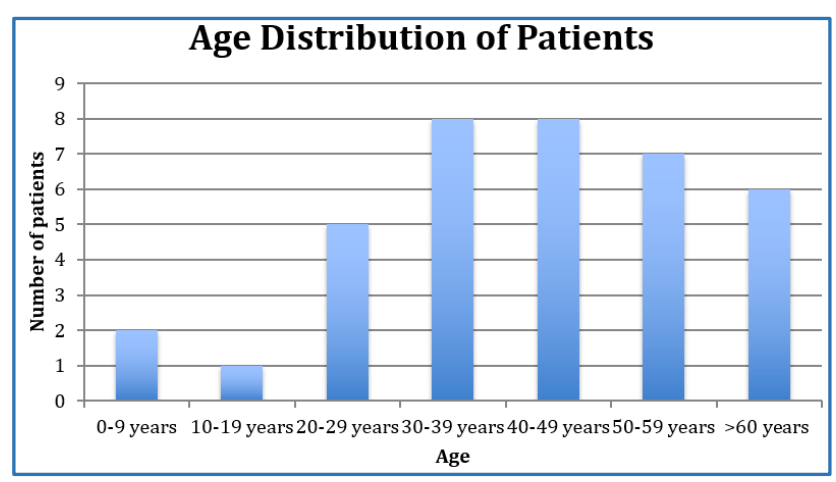

Fig. 1

\begin{tabular}{|c|c|}
\hline Presenting Feature & Number of Patients \\
\hline Fever & 25 \\
\hline Diarrhoea & 24 \\
\hline Breathlessness & 18 \\
\hline Cough & 12 \\
\hline Sore Throat & 7 \\
\hline Headache & 5 \\
\hline Myalgia & 4 \\
\hline Drowsiness/Lethargy & 2 \\
\hline Expectoration & 2 \\
\hline Rhinorrhoea & 1 \\
\hline Chest pain & 1 \\
\hline \multicolumn{2}{|c|}{ Table 1 } \\
\hline
\end{tabular}

\begin{tabular}{|c|c|}
\hline $\begin{array}{c}\text { Duration of Complaints } \\
\text { (in days) }\end{array}$ & $\begin{array}{c}\text { Number of } \\
\text { Patients }\end{array}$ \\
\hline 1-2 days & 4 \\
\hline 3-4 days & 8 \\
\hline 5-6 days & 11 \\
\hline >6 days & 14 \\
\hline \multicolumn{2}{|c|}{ Table 2 } \\
\hline
\end{tabular}

\section{REFERENCES}

1. Knobler SL, Mack A, Mahmoud A, et al. The threat of pandemic influenza: are we ready? Workshop summary. The story of influenza. Washington (DC): National Academies Press (US) 2005.

http://www.ncbi.nlm.nih.gov/books/NBK22148/

2. 2009 H1N1 Flu (Swine Flu) and you. http://www.cdc.gov/h1n1flu/qa.htm

3. World Health Organization. Pandemic (H1N1) 2009update 109. Geneva: WHO, 2010. www.who.int.

4. Novel H1N1 flu: background on the situation. http://www.cdc.gov/h1n1flu/background. htm.

5. Pandemic influenza A (H1N1). Epidemiological trends, November case fatality ratio. http://www.mohfwH1n1.nic.in/epidemiological.html

6. Kumar TCN, Shivakumar NS, Deepak TS, et al. H1N1infected patients in ICU and their clinical outcome. North American Journal of Medical Sciences 2012;4(9):394-8.

7. Swine flu in India: 2,035 succumb to the H1N1 virus. 2015. http://www.thehealthsite.com/news/swine-fluin-india-2035-succumb-to-the-h1n1-virus.

8. Center for Disease Control. 2009 H1N1 early outbreak and disease characteristics. CDC, Atlanta: 2009. http://www.cdc.gov/h1n1flu/surveillanceqa.htm

9. Rothberg MB, Haessler SD, Brown RB. Complications of viral influenza. Am J Med 2008;121(4):258-64.

10. Banu A, Sathishchandra H, Anand M. Outbreak of H1N1 influenza among the health care personnel in a tertiary care hospital. Journal of Clinical and Diagnostic Research 2011;5(6):1234-6.

11. Nelliyanil M, Basha R, Sharada MP. Profile of the novel flu patients who were admitted to two government hospitals in Bangalore. AMJ 2010;3(6):340-3.

12. Kumar B, Pati DR, Khanna M, et al. Age-sex distribution and seasonality pattern among influenza virus infected patients in Delhi, 2009-2010. Indian Journal of Community Medicine 2012;37(1):57-8.

13. World Health Organization. Influenza Pandemic (H1N1) 2009. Geneva: WHO, 2009:1-5.

http://www.who.int/bulletin/volumes/89/7/11086173.pdf

14. Canadian Ministry of Health. Ontario novel H1N1 influenza-a virus epidemiological summary. Ministry of Health, 2009.

http://ocfp.on.ca/docs/publications/information-onthe-novel-h1n1-influenza-virus-fr-primary-carepractitioners.pdf?sfvrsn $=2$

15. Oliveira WK, Carmo EH, Penna GO, et al. Pandemic H1N1 influenza in Brazil: analysis of the first 34,506 notified cases of influenza-like illness with severe acute respiratory infection (SARI). Euro Surveill 2009;14 (42):pii 19362.

16. Sax H, Uckay I, Richet H, et al. Determinants of good adherence to hand hygiene among healthcare workers who have extensive exposure to hand hygiene campaigns. Infect Control Hosp Epidemiol 2007;28 (11):1267-74

17. Ojanuga DN, Gilbert C. Women's access to health care in developing countries. Social Sci Med 1992;35(4):613-7.

18. Fiore AE, Shay DK, Broder K, et al. Prevention and control of seasonal influenza with vaccines: recommendations of the advisory committee on immunization practices (ACIP), 2009. MMWR Recomm Rep 2009;58(RR-8):1-52. 
19. Klein SL, Passaretti C, Anker M, et al. The impact of sex, gender and pregnancy on 2009 H1N1 disease. Biology of Sex Differences 2010;1(1):5.

20. Ramakrishna K, Sampath S, Chacko J, et al. Clinical profile and predictors of mortality of severe pandemic (H1N1) 2009 virus infection needing intensive care: a multicentre prospective study from south India. Journal of Global Infectious Diseases 2012;4(3):145-52.

21. Domínguez-Cherit G, Lapinsky SE, Macias AE, et al. Critically ill patients with 2009 influenza $A(H 1 N 1)$ in Mexico. JAMA 2009;302(17):1880-7.

22. Denholm JT, Gordon CL, Johnson PD, et al. Hospitalised adult patients with pandemic (H1N1) 2009 influenza in Melbourne, Australia. Med J Aust 2010;192(2):84-6.

23. Nelliyanil M, Basha R, Sharada MP. Profile of novel flu patients admitted in two government hospitals in Bangalore. AMJ 2010;3(6):340-3.

24. Tambe MP, Parande M, Jamkar AV, et al. An epidemiological study of confirmed H1N1 admitted cases in an infectious disease hospital, Pune. Journal of Krishna Institute of Medical Sciences University 2012;1(2):81-90.
25. Skowronski DM, Janjua NZ, de Serres G, et al Effectiveness of ASO3 adjuvanted pandemic H1N1 vaccine: case control evaluation based on sentinel surveillance system in Canada, autumn 2009. BMJ Research 2011;342:c7297.

26. Thompson WW, Shay DK, Weintraub E, et al. Influenzaassociated hospitalizations in the United States. JAMA 2004;292(11):1333-40.

27. Barclay L. H1N1 critical illness mostly affects young patients and is often fatal. Medscape Medical News, 2010. http://www.medscape.com/sites/swine-flu.

28. Louriz M, Mahraoui C, Azzouzi A, et al. Clinical features of the initial cases of 2009 pandemic influenza A (H1N1) virus infection in an university hospital of Morocco. Int Arch Med 2010;3:26.

29. Bhatt KN, Jethw SC, Bhadiyadar D, et al. Study of clinical profile in patients with 2009 H1N1 influenza in Surat district, June 2009-March 2010. JAPI 2012;60:15-9.

30. Anand R, Gupta A, Gupta A, et al. Management of swineflu patients in the intensive care unit: our experience. Journal of Anaesthesiology, Clinical Pharmacology 2012;28(1):51-5. 